\title{
"Close to the Nature, Hand in Hand with Fuwa": Framing Environmental Issues in Biding and Preparations for the Beijing Olympic Games
}

\author{
Jackie Gage ${ }^{1}$, Shuang $\mathrm{Xie}^{2} \&$ James Cantrill ${ }^{2}$ \\ ${ }^{1}$ University of Illinois, Urbana-Champaign, USA \\ ${ }^{2}$ Department of Communication and Performance Studies, Northern Michigan University, USA \\ Correspondence: Shuang Xie, Department of Communication and Performance Studies, Northern Michigan \\ University, 1401 Presque Isle Ave, Marquette, MI 49855, USA. Tel: 1-906-227-1644. E-mail: sxie@nmu.edu
}

Received: April 25, 2013 Accepted: May 13, 2013 Available online: May 25, 2013

doi:10.11114/smc.v1i1.148 URL: http://dx.doi.org/10.11114/smc.v1i1.148

\begin{abstract}
Given China's negligent environmental history and political battles regarding other issues, creating and disseminating a positive message surrounding the 2008 Olympic Games became a challenge for the Beijing Organizing Committee for the Olympics Games (BOCOG). This study explores material published by BOCOG on its official website and examines how environmental issues were framed in the process of bidding and preparations for the Beijing Olympiad. We find that BOCOG used different framing strategies for external and internal publics. The dominant master frame targeted at the external public could be considered a "gain-versus-loss" frame promoting acceptance of the Games. For internal publics, in addition to a gain-versus-loss frame, BOCOG also adopted "identity and national pride" as master frames.
\end{abstract}

Keywords: Beijing Olympics, environmental communication, framing

\section{Framing Environmental Issues in Biding and Preparations for the Beijing Olympic Games}

On August 8, 2008 the opening ceremonies for the Beijing Olympic Games initiated one of the most controversial Olympiads in modern history. Although the awarding of that Olympiad to the People's Republic of China (PRC) was long-overdue in some eyes, the bidding and planning processes were marred by controversy and difficulty. After a failed bid attempt in 1993 for the 2000 Games (GamesBids.com, 2009), Beijing officials brought an unbeatable offer to the table for the 2008 games and won the rights to host the Olympics for the first time in the country's history. Once the decision was announced on July 13, 2001 by International Olympic Committee (IOC), President Juan Antonia Samaranch, "the city erupted into a party" (Ong, 2004, p. 35). Nonetheless, while the Chinese people were celebrating, Beijing Olympic officials were bracing for a difficult path, as many around the world did not support the PRC's victory. Critics argued that the PRC's human rights record, closed society, communist regime and environmental problems made it difficult to envision the Olympic ideals being realized in Beijing.

As international sports become more prominent in the context of both popular culture and geopolitical intrigue, message campaigns managed by erstwhile host countries to promote their Olympic dreams have become important fodder for communication analysis. Cull (2008) argues that sport has become a powerful tool for international relationship-building and, in particular, the Games have come to be as much a political event as a sports spectacle (Kanin, 1981). In addition, Theodoraki (2009) observes that the manner in which Olympic organizing committees communicate their intentions and anticipates impacts of hosting the Games serves a vital branding function for not only any given Olympiad but also for the host country itself. And, in a world where environmental issues have taken the stage as a key component in a nation's attempt to participate in the global marketplace, events such as the Olympic Games can provide a useful venue for communication analysis in an international context.

Although many facets of various Olympic bids warrant discussion, our intent is to specifically examine the environmental exigence that influenced Beijing's campaign. Following a brief overview of the PRC's 
environmental and Olympic history, the bidding and planning process will be discussed in depth. Next, we provide an overview of the implicit frames that accompany campaigns directed at promoting the public face of events such as the Beijing Olympics. Finally, we will discuss how various message tactics were utilized by the Beijing Organizing Committee for the Olympics Games (BOCOG) to frame communications directed at both internal and external publics and how this helped the 2008 become the most successful Olympiad in terms national and international support and involvement. In the end, 10, 942 athletes from 204 countries participated in the Games (International Olympic Committee, 2009) and a Nielson study (2008) finds the Beijing Game attracted 4.7 billion viewers, which constituted 70 percent of the world's population.

\section{The PRC's Environmental and Olympic History}

China is believed to have one of the oldest cultures in the world and ancient principles continue to buttress a collective code of ethics (City University of New York, 1995). Significantly, the religion of ancient China represented a form of nature worship wherein "nature itself needed careful tending" (Berthrong, 2003, p. 376; cf. Elvin, 1998; Shinn, 2009). However, with a population boom in the late-Imperial age, resources were increasingly exploited beyond replacement rates and started becoming scarce.

The PRC, created in 1949 under Chinese Communist Party leader Mao Zedong, focused primarily on economic development during the early decades of the Republic and the PRC's leadership believed that man could and should "conquer nature" by adopting emergent Maoist ideals (Liu \& Diamond, 2005; Shapiro, 2001). In the 1950 s, production of industrial goods skyrocketed while the agricultural sector plummeted as peasants were forced off land and into factories (Sanders, 1999). A constant emphasis on economic expansion ruled the day as decentralization occurred, in turn spurring on economic growth beyond metropolitan areas (Shildo, 1990). In short, environmentally benign, sustainable natural resource policy took a backseat to industrialization. Mao's leadership throughout the 1950s and 1960s led to not only environmental neglect, but also significant degradation of natural resources. Whatever meager attempts were made to protect the natural environment were largely thwarted by a widespread lack of authority in the countryside and little coordination between existing environmental agencies (Jahiel, 1998).

As the PRC became a major exporter of goods during mid-Twentieth Century, environmental dilapidation became a cause for concern among importing nations. In response, the Chinese Cultural Revolution began making significant strides by the early 1970's and the concept of environmental protection was rejuvenated and widely supported. Yet progress was spotty and the environment continued to degrade. After Mao's death, Deng Xiaoping assumed power and began implementing a very different agenda including privatized farming, light industry and agriculture, and price-based agriculture (Sanders, 1999). The central government essentially maintained absolute power through the promulgation of five-year plans that proved to be a foundation of for ushering China into an increasingly competitive position among industrialized nations.

Despite the somewhat iron-grip of economic authoritarianism in mainland China, the Deng regime also included the first Environmental Protection Law for the PRC in 1989, which later became "fundamental state policy" (Edmonds, 1994, p. 71). The following decade was highlighted by the inception of the Ministry of Urban and Rural Construction and Environmental Protection which was later changed to the National Environmental Protection Agency (NEPA). Coincidentally, the PRC government began to see the need to cultivate a more positive international reputation so as to assert regional and global influence (Kurlantzick, 2006), and one avenue to such esteem was thought to be found in the Olympic movement (cf. Manheim, 1990).

As one of the most powerful countries in the world, dominance on the playing field came naturally to the Chinese people. China's first involvement with the modern Olympic movement came in 1899 when modern Olympic founder Pierre de Coubertin invited Chinese athletes through Qing Dynasty rulers to the 1896 Games in Athens. Although the Qing government declined the invitation due to their unfamiliarity with organized sports events, the Olympics were included in national media coverage for the next three decades. In 1931, the IOC bestowed recognition upon the All-China Athletic Association whereupon China finally began sending delegations to the Games (Chinese Olympic Committee, 2008). The PRC's breakout Olympic year did not come until the 1984 Los Angeles Games in which 224 athletes competed and brought home fifteen gold, eight silver and nine bronze medals finishing fourth in the overall medal standings (Chinese Olympic Committee, 2008). Hosting an Olympic Games was the next logical step. China had become the world's most populous country and the fourth largest in area. Its economy was also currently growing at the fastest rate of any major nation. Nonetheless, its environmental problems were also the most severe in the world and worsening (Liu \& Diamond, 2005). Such were the issues that had to be addressed as Beijing prepared to bid to showcase a modern Olympiad. 


\section{Bidding for the Olympic Games}

Beijing initially bid for the rights to host the Olympic Games in 1993 but was unsuccessful as the rights to host the 2000 Games awarded to Sydney, Australia. Concurrently, the PRC was a budding Olympic powerhouse and was increasingly competitive on the world sports stage. It was also at this time that the PRC was involved in international debates involving environmental degradation and human rights violations, thereby casting a pall over Beijing's bid. Adopting the lead set in 1994 at the Lillehammer Games, the 1998 Olympiad in Nagano, Japan marked the first time the IOC adopted a formal protocol for applicant countries to follow regarding environmental issues (Cantelon \& Letters, 2000). One of the pillars of Sydney's winning Olympic bid was a focus upon the idea of sustainable development giving it the cutting edge over Beijing by incorporating the newest Olympic ideal. As Beyer (2006) notes and the IOC reiterated in the revised version of the Olympic Charter, the Olympics is more than merely an athletic competition. Recognizing the importance of the environment and sustainable development, the IOC in 1996, added an important element regarding environmental protection to the Olympic Charter: "The IOC's role with respect to the environment is: to encourage and support a responsible concern for environmental issues, to promote sustainable development in sport and to require that the Olympic Games are held accordingly" (Olympic Charter, 1996, Chapter 1, Rule 2).

As host for the 2000 Games, Sydney's environmental strategies included public transport access, solar power applications, green building material selection, recycling of construction waste, energy and water conservation, and wetland restoration. Athens, the host of 2004 Olympiad, adopted eco-friendly vehicles and eco-friendly building materials aw well, used new energy technology, and planted over 12 million small trees and bushes throughout the Greek capital (IOC, 2009). Thus, in addition to showing the IOC that China was well-positioned to highlight its culture while guaranteeing successful Games per se, Beijing also had to be committed to an environmentally benign event in hosting the games.

However, before a city can bid to host an Olympic Games, it must first be named as a candidate. It was not until November 1998 that China's Central Committee formally decided to offer Beijing as a candidate for the 2008 Olympics. A formal application from the Beijing government entered the city into the running to become a candidate city. The IOC accepted Beijing as a candidate city later that month and Beijing officials immediately started to prepare a new bid (Ong, 2004). The Beijing 2008 Olympic Games Bid Committee (BOBICO) was officially created in September 1999 (BOCOG, 2002) and the organization spent the next two years to bring the Olympics to the PRC for the very first time.

While Beijing was bidding for the Olympic Games, China made several promises to the IOC regarding improvements to the local environment, among other things protecting the health of Olympic athletes from the ambient air pollution prominent in Beijing. These promises were made to strengthen Beijing's bid for the Olympics and gain support throughout voting members of the IOC as well as the international sporting community. In that the bid was a first step in Beijing realizing its Olympic quest, it became an integral part in socially constructing the Games to demonstrate the central government's renewed concern for the environment, as well as towards sustainable green development throughout the country in the future.

The new bid worked to address concerns voiced by the IOC during the 1993 attempt, in particular environmental degradation in China and the potential for harm those conditions had for the Olympic Games per se. This time, to the extent the environmental impact of the Games had been a growing concern among citizens and in the international community, Beijing demonstrably embraced the new Olympic "green" ideal in its second bid with significant consideration taken regarding the environment. BOCOG used its bid for the 2008 Games to address many of these ideals and to gain support amongst citizens, appropriating significant funding to issues such as air pollution from industry, construction and transportation (GamesBids.com, 2009). For example, environmental promises encompassed an increase in standards such as vehicle emissions, clean fuels in 90 percent of public busses and 70 percent of taxis, increasing the wastewater treatment capacity, constructing hazardous waste disposal systems and the relocation of more than 200 industrial enterprises (United Nations Environment Programme, 2007). Additionally, the equivalent of $\$ 12.2$ (US) billion was allocated for environmental projects over nine years (BOCOG, 2002) making Beijing's environmental budget the largest in Olympic history. Along the way, the PRC leadership ramped-up their public rhetoric to advertise the setting of such an ambitious environmental agenda. As a result, BOCOG's environmental projects earned credibility and respect among athletes, countries and environmental organizations (Economy, 2007). Indeed, more than a year before the opening ceremonies, the Beijing government was extolling the virtues of its green-planning process by declaring that all of the environmental promises made in the 2001 bid had been met by the end of 2007 (Yuan, 2008). 
Many viewed Beijing's win as inevitable due to the PRC's world economic power and growing Olympic dominance. However, The Olympic Games also presented the PRC with the opportunity to simultaneously address international concerns on a variety of fronts. In that this was also the first formal public communication BOBICO had regarding the environment, a focus upon sustainability meant that the message appeal had to be shaped from the beginning in a very specific way. As such, environmental foci became driving elements in the framing of the Games to the world at large.

\section{Frames, Communication and the Seduction of Publics}

One approach to understanding the extent to which the bidding process for the Beijing Olympiad was strategically constructed to deal with the environmental exigence of on-the-ground conditions in the PRC focuses on the role played by the project's strategic framing given the culture and cognitions of both the Chinese people and the international audience. Gray (2003) defines framing as "the process of constructing and representing our interpretations of the world around us through a construction of categories based on our experiences relative to previous interpretations" (p. 12). Entman (1993) states that "to frame is to select some aspects of a perceived reality and make them more salient in a communicating text, in such a way as to promote a particular problem definition, causal interpretation, moral evaluation, and /or treatment recommendation of the item described" (p. 52). For Entman, frames have various functions including defining problems, diagnosing causes, making moral judgments, and suggesting remedies.

For mega-events like Olympic Games, Zaharospulous (2007) notes that media framing is, arguably, the most important concern in the public sphere. In a sense, "the Olympics are and were whatever the media portrayed them to be" (p. 239). When examining the media frame of 2004 Olympic Games in Greek, Zaharospulous observed that how the 2004 Olympic Games were framed "tell[s] us about journalistic decisions, values, and practices" (p. 237) and also can "point to potential effects of such practices" (p. 237, cf. Billings and Eastman, 2003).

Variants on the framing theme can be considered as two sides of the very same coin. One perspective presents frames as theoretical, mental constructions used to interpret, among other stimuli, communication in the public sphere (e.g., Gross \& D'Ambrosio, 2004). The alternate perspective holds that frames are embedded in the structure of instrumental discourse and serve to organize narratives in coherent ways (e.g., Schlechtweg, 1996). At the intersection of cognitive and narrative framing lies the interpretive landscape of meaning and the extent to which the targets of advocacy more-or-less resonate with the arguments and portrayals agents produce. Here, the choices agents make in framing issues for public consumption is of the utmost importance when promoting projects in the competitive marketplace of ideas. That is, as an agent consciously or tacitly selects and uses a dominant frame when casting arguments in the public sphere, the quintessential objective must be to have the target population interpret the message using that particular frame as an organizing scheme (Davis \& Lewicki, 2003; Pinker, 2007).

As a theoretical concept, the idea of a "frame" has enjoyed wide application in a variety of research traditions. The concept is well-entrenched in fields such as psychology (e.g., Galotti, 2009), argumentation, (e.g., Hample, Werber, \& Young, 2009), persuasion (e.g., Henningsen, et al., 2003), psycholinguistics (Lakoff, 2004), and political science (e.g., Beer \& De Landtsheer, 2004); it has also found a home in a variety of applied domains such as health communication (e.g., Reinhart, et al., 2007), conflict management (e.g., Brummans, et al., 2008), and social movement dynamics (Dardis, 2007). In particular, approaching frames from either a narrative or cognitive vantage has enjoyed a good deal interest by environmental communication scholars focusing on media studies (e.g., Shanahan \& McComas, 1999), public participation (e.g., Davis \& Lewicki, 2003), watershed management (e.g., Dewulf, et al., 2007), and environmental risk analysis (e.g., Leiserowitz, 2005). Clearly, as an analytic construct, framing has enjoyed considerable attention, suggesting it's applicability to the BOCOG's campaign to host the Olympics and manage public perceptions of the event as time went along.

One of the central elements in the framing of narratives and subsequent frame-bound interpretations thereof is the presence of "master frames" that organize and appeal or depiction around one or more dominant themes (Lakoff, 2004). For example, an "environmental justice" frame provides a trope for both the advocacy against and the interpretation of discourse related to environmental degradation to extend beyond humans harming their environment to humans, in doing so, harming other humans (cf. Bullard, 1993; Pezzullo, 2001). In addition, Hunt, Benford, and Snow's (1994) analysis suggests that master frames may gain a good deal of their perceptual influence to the extent they are linked to the self-concepts of a target group or their group identity. And the association need not be a conscious act on the part of either narrative agent or the receptive mind, though it 
would hardly be considered a strategic rhetorical move if the disseminating party were not well aware of framing decisions implicit in any advocacy campaign.

Traditional analyses of public outreach campaigns associated with the Olympic Games have focused on the marketing of such events to provide host cities and nations with a "branding" that commences with the opening ceremonies for each biennial event. For example, in the case of the Beijing Olympiad, Bu (2009) contends that brand value focused on images of "harmony" and "green" approaches to the Games. In contrast, we believe the overall image of the Beijing Olympics was the cumulative and strategic product of how the Games were framed in the years leading up to 2008 .

\section{Framing the Beijing Olympics}

Because of a blemished environmental and social history, gaining support for the Beijing Olympics in the international arena, even after the city won the rights to host the Olympiad, was a major undertaking. Most importantly, BOCOG had to constantly communicate at home and abroad about the planning process, new policies and procedures, and goals for the Games. Such information had to be framed to present a precise message to the public in an attempt to gain support, specifically for the environmental plans and policies relevant to the 29th Summer Olympiad in the modern era (Brewer \& Gross, 2005).

With the environment as a cornerstone of Beijing's successful Olympic bid, work had to continue throughout the planning process to achieve the tangible goals of the Games. With so much at stake, BOCOG continued campaigning worldwide. Although the Games were widely supported during the bidding process, there were still more than a few skeptics. Because of the opposition, BOCOG had to develop the prospect for the Games and its image to garner support from both internal and external publics. BOCOG understood that to control response and reaction, they had to control the message ( $\mathrm{Bu}, 2009)$. In particular, the PRC government had to manage the impressions of the international, external public first and foremost; given the collectivist culture and authoritarian strictures on the Chinese mainland, impression management directed at the internal homeland public was of secondary importance. Nonetheless, each of these two, distinct publics reflected unique constraints regarding how the environmental problems occasioned by the Games should be addressed, therefore requiring the Beijing government to employ a pair of dominant and recessive master frames in the BOCOG campaign.

\section{Framing for an External Public}

The external public BOCOG faced consisted primarily of other Olympic-team countries. However, the external public also includes international environmental organizations, national Olympic committees and concerned governments. These groups were concerned for athletes' ease at the Olympic experience, exposure to pollution from transportation and other sources, and long-term health effects after the Games among other environmental issues. For the external publics, messages detailed improvements to air quality, green construction practices, water system improvements and transportation system expansion. The dominant master frame for these messages could be considered a gain-versus-loss frame promoting acceptance of the Games.

The gain-versus-loss master frame prompts action more to prevent a loss than to capture a gain (cf. Gerend \& Shepherd, 2007; Shmueli, Elliott, \& Kaufman, 2006) and, in many respects, is similar to individuals' and nations' tendencies to minimize their losses while maximizing their gains, or the "minimax principle" (Hood, 2002; Schlenker, 1980). Although this idea is commonly understood in the Chinese culture, internationally it is not an accepted ideal everywhere. Employing this master frame allowed BOCOG to communicate with others around the globe that the PRC was concerned for the international athletes and without their support and assistance the Olympics would not be as healthy or environmentally friendly as possible. In the case of the Beijing Olympics, the loss was to be found in potential problems for athletes attending the games; the gain being a healthier, cleaner environment during and following the Beijing Olympics. It was important in this instance to appeal to the international audience's personal gain or loss and to demonstrate that the loss was imminent without support and the gain was vital for a successful Olympiad to come about.

The gain-versus-loss master frame appealed to the international desire for a strong stance toward environmental standards, resulting in a safe and healthy Olympics, and thereby gaining support for the PRC's efforts to create a "green" Olympics. In discourse, it emphasized the traditional Taoist idea that all gain requires loss of opportunity, at least to some extent. For example, in 2005 BOCOG released a "Road to 2008: Environmental Themes and Guidelines" discussing the prevention and control of air pollution, water treatment, solid waste management and more (BOCOG, 2006). More importantly, the information contained pertained directly to international audiences and the direct investment China was contributing in the name of the environment. Beijing boasted the involvement of its people and the large strides made toward "Green Olympics". These 
messages highlighted the positive effects of the green efforts toward improving Beijing's environment, thereby eliciting a positive response from the international community.

The "Green Olympics" concept also highlighted the gain-versus-loss master frame as BOCOG regularly used it to link the PRC to environmentalism in general. BOCOG's desired response from the message was public support from other national Olympic committees and minimal international opposition before and during the Games. One of the most important and influential pieces of communication in this regard was the Beijing Olympic Action Plan (BOAP). The BOAP discussed explicit plans made by BOCOG in conjunction with non-governmental organizations (NGOs) and national Olympic governing bodies regarding many aspects of the Beijing Games with a specific section focusing on the environment. The BOAP was meant to inform them about plans to regulate pollutants and overall improve the environment for not only the Beijing Olympic Games but the future as well. The BOAP discussed several areas of environmental concern that would be addressed and improved during the Olympic planning process. The gain-versus-loss message framing communicated to the world that without support nationally and internationally, Beijing could not host the Green Olympics BOCOG had promised in securing the Games.

Examples of this frame can be found in the BOAP. The Green Olympic Action plan is a subset of the BOAP and was signed by the BOCOG, municipal authorities, and numerous NGOs. The plan utilizes the master framing throughout its entire length. For instance, "The concept of Green Olympics becomes more and more popular among Beijing Citizens... and a solid foundation has been laid for the strategy of the Green Olympics..." (BOCOG, 2003). The plan goes on to state, "[it] gives full consideration to present status with first priority given to meeting the demands of the people" (BOCOG, 2003). Focusing on the people and providing guidelines to green living such as "solid wastes should be reused or recycling and all the hazardous wastes should be safely treated and disposed... it will also be encouraged to use cleaner energy to replace coal-burning... give priority to public transportation and rail transportation" (BOCOG, 2003). Although these are measures taken by the people in Beijing, the effects of these improvements appeal to international audiences. Indeed, though the PRC had a good deal to gain from the Games per se, external publics were less concerned with the PRC's outcome than for any outcome affecting themselves. For example, The China Daily conducted a survey in 26 countries and regions about their interest in tourism in China. Forty-five percent of 26, 000 people polled expressed their intention to travel to China after seeing the opening ceremony and 51 percent showed their interest after seeing the closing ceremony (China Daily, 2008). In a gain-versus-loss framework, the international community came to understand that the achievement of their gains, as well as the avoidance of and loss, depended on the PRC creating a Green Olympics that benefited its people and avoided the loss of national prestige in and out of the sporting arena.

\section{Framing for an Internal Public}

Internally, the Chinese people were concerned about the cost of environmental improvement, potential displacement and pollution as a result of Olympic construction, and the delivery of promised long-term environmental benefits. In turn, BOCOG primarily utilized a secondary identity master frame to communicate with the residents of Beijing and beyond so as to appeal to their strong sense of national pride. The PRC has a long cultural history that many of its citizens strongly identify with. Appealing to the cultural identity of the citizens helped recruit support for the games, solicit volunteers and simply promote the event throughout the country. To address some of the concerns voiced nationwide, BOCOG utilized the Beijing Municipal Government as it is responsible for matters related to environmental and natural resource management encompassing all Beijing based Olympic venues and activities (BOCOG, 2002). Empowering the local government to oversee Olympic planning effectively decentralized the decision making process, giving more power to citizens to participate in the shape of the Olympiad. This also appealed to citizen's strong sense of identity. Communications discussing this matter were framed in a way that allowed the internal public for the Games to personify the ostensible nationalistic fervor for environmental protection.

The identity master frame can be seen in communications such as a news article on China's official website: “'The Games gave us a more open and mature attitude,' said Professor Hu Jiqing from Nanjing University. 'This attitude featured magnanimity, tolerance and pluralism. More importantly, it embodies a more confident nation"” (Xinhua News Agency, 2008). Such demonstrates the effectiveness of the master identity frame in nurturing the strong association the Chinese people have with their country. Finally, BOCOG developed several initiatives to spread the message of environmental values among the public including "The Green Community" and "Green Home Campaign," the "One Day, No Engine Sounds" Campaign, "The Beijing Green Map Initiative," and the "Close to the Nature Hand in Hand with Fuwa" exhibition. Each of these communications demonstrated what 
individuals and communities could do to improve the environment, making the issue salient and personal (United Nations Environment Programme, 2007; cf. Kraft \& Wurtz, 1996).

Additionally, the dominant gain-versus-loss master frame also assisted BOCOG in maintaining support internally as national pride was wed to international prestige. As each goal in the planning process was reached, news media assisted in spreading the positive message and reinforced the idea that the Games were gaining a benefit for the country and its people. As a result of national support and assistance, many of Beijing's bid commitments were made ahead of schedule, and green initiatives began early and lasted longer with stronger effects throughout the process (United Nations Environment Programme, 2007).

The melding of the gain-versus-loss master frame with the identity master frame was also used to promote a future sense of identity for the Chinese people. This tactic was directed more towards children through the use of the five Olympic mascots promoting environmental awareness.

Fuwa, the official mascots also carried a message of Chinese national identity, as well as Beijing's Commitment to an environment-friendly Game. Fuwa, literally in Chinese, meant lucky kids. Four of five Fuwa respectively represented four of China's most popular animals - fish, panda, Tibetan antelope, and swallow. The last one represented the Olympic Flame. Five Fuwa also embody the five fundamental natural elements in Chinese culture: metal, wood, water, fire, and earth. The mission of Fuwa was to convey friendship, prosperity and peace to the world. Beibei, the Fuwa of fish and water symbolized prosperity and harvest. Jinging, the Fuwa of panda with a headdress of lotus, was the symbol of the lush forest and the harmonious relationship between human and nature. Huanhuan, the Fuwa of fire, represented the Olympic sprite, and the enthusiastic characteristics of Chinese people. Yingying, the one of Tibetan antelope, was a symbol of the vastness of China's landscape. Also, the selection of the Tibetan Antelope reflected Beijing's commitment to a Green Olympics. Nini, the Fuwa of a golden-winged swallow, symbolized the infinite sky and spread good luck wherever she flew. The names of five Fuwa, when putting together, form "Beijing Huanying Ni", which means "Welcome to Beijing." To sum up, the use of Fuwa as the official mascots of the Game in Beijing expressed Chinese people's pride of their country and Chinese people's desire to reach out to the world through the Game In addition, he pervasive use of Fuwa across the country demonstrated the effect of green living on the environment over time and enforced the idea that the environment needed help to sustain the national identity (United Nations Environment Programme, 2007).

\section{Conclusion}

The IOC placed immense faith in the Beijing bidding committee to host a peaceful, clean and competitive Olympics. Lofty promises were made during the bidding phase, and the PRC was thrust front and center to reach and exceed those goals on the way to hosting the largest Olympic Games in history. As a result, the PRC was also well on its way to making the country more of an environmentally friendly place. With the international spotlight on the entire country, internal and external publics became major factors during the planning process.

With years of planning needed to create the Olympic Games, maintaining support throughout the process became vital to success. Due to the PRC's poor environmental history in addition to political battles regarding other issues, creating and disseminating a positive message surrounding the Games became a challenge for BOCOG. Using framing to shape the messages disseminated to the public allowed BOCOG to predict and shape the public's reaction. The gain-versus-loss frame enticed international support by showing each country what it stood to gain from a healthy Games supported world-wide versus what could potentially be lost by each country if the Games took place in a polluted, congested and unhealthy setting. Identity frames utilized nationwide by BOCOG and national media alike appealed to each person's sense of self to assist in gaining support.

Most communications sent out by BOCOG had explicit intentions. In the case of the Beijing Olympics, the PRC knew the event was a milestone in history and treated it as such. Communicating with each public was crucial, specifically regarding environmental activities. Once aspects of the ongoing campaign were pitched and received, master frames that were compatible with the social and cultural selves of those in and out of the PRC were used as interpretative screens for the information provided in order to more easily understand it with reference to their own experiences. BOCOG utilized this innate response to elicit a particular response from the publics receiving communication based on new information with respect to previous information.

Although the PRC was largely successful in managing its public face leading up to the 2008 Olympiad, we cannot conclude our analysis without recognizing that the reality of life on the ground during and after the Games did not necessarily match the BOCOG hype. As Economy (2007) observed even before the Games commenced, there was a darker underbelly to what the national and international audience saw: 
Since Beijing promised in 2001 to hold a "green Olympics" in 2008, the International Olympic Committee has pulled out all the stops. Beijing is now ringed with rows of newly planted trees, hybrid taxis and buses are roaming its streets (some of which are soon to be lined with solar-powered lamps), the most heavily polluting factories have been pushed outside the city limits, and the Olympic dormitories are models of energy efficiency. Yet in key respects, Beijing has failed to deliver. City officials are backtracking from their pledge to provide safe tap water to all of Beijing for the Olympics; they now say that they will provide it only for residents of the Olympic Village. They have announced drastic stopgap measures for the duration of the games, such as banning one million of the city's three million cars from the city's streets and halting production at factories in and around Beijing (some of them are resisting). Whatever progress city authorities have managed over the past six years -such as increasing the number of days per year that the city's air is deemed to be clean -- is not enough to ensure that the air will be clean for the Olympic Games. Preparing for the Olympics has come to symbolize the intractability of China's environmental challenges and the limits of Beijing's approach to addressing them (p. 46).

Nonetheless, the PRC was quite effective in managing the impressions of the international community by getting the external public to focus on what Beijing was doing to minimize environmental problems in order to maximize the benefits the Games would incur. Rhetorically, the master framing of the campaign also mobilized the Chinese people behind the green banner of the Olympiad's public face. And, in the end, scholars of environmental communication have been left with a fine example of a government's skillful use of narrative and psychology in the discourse of the public sphere.

\section{Limitations}

This project primarily adopts qualitative approaches to analyze how the PRC frames the environmental issues when applying for the host of 2008 Olympic Games. The in-depth analysis yields insightful and convincing findings. Arguably however, to adopt the mixed method which also involves quantitative approaches will make this project more methodological sound and provide a more comprehensive test of our research questions, and consequently to make the findings more generalizable about how the national governments' framing of the specific issues when applying for host major sports events will work.

\section{References}

Beer, F. A., \& Landtsheer, C. (2004). Metaphorical world politics. East Lansing: Michigan State University Press.

Benford, R. D., \& Snow D. A. (2000). Framing processes and social movements: An overview and assessment. Annual Review of Sociology, 26, 611-39. http://www.jstor.org/stable/223459

Berthrong, J. (2003). Confucian views of nature. In H. Selin (Ed.), Nature across cultures: Views of nature and the environment in non-western cultures (pp. 373-392). Dordrecht, Netherlands: Kluwer Academic Publishers.

Beyer, S. (2006). The green Olympic movement: Beijing 2008. Chinese Journal of International Law , 5, 423-440. http://chinesejil.oxfordjournals.org/content/5/2/423.full.pdf + html

Billings, A. C., \& Eastman, S. T. (2003). Framing identities: Gender, Ethnic, and National Parity in Network Announcing of the 2002 Winter Olympic Games. Journal of Communication, 53(4), 569-586. http://dx.doi.org/10.1111/j.1460-2466.2003.tb02911.x

BOCOG. (2002). The official website of the Beijing 2008 Paralympic Games. Retrieved September 18, 2009 from Organizational Area: http://en.paralympic.beijing2008.cn/organization

BOCOG. (2003). Beijing Olympic Action Plan. Retrieved September 20, 2009 from The Official Website of the Beijing 2008 Olympic Games: http://en.beijing2008.cn

BOCOG. (2005). Green Olympics in Beijing 2004. Retrieved September 18, 2009 from Beijing 2008: One World One Dream: http://en.beijing2008.cn

BOCOG. (2006). Road to 2008: Green Olympics in Beijing . Retrieved January 20, 2010 from The Official Website of the Beijing 2008 Olympic Games: http://en.beijing2008.cn

Brewer, P. R., \& Gross, K. (2005). Values, framing and citizens' thoughts about policy issues: Effects on content and quantity. Political Psychology, 26, 929-948. http://dx.doi.org/10.1111/j.1467-9221.2005.00451.x

Brummans, B. H., Putnam, J. M., Gray, L. L., Hanke, B., Lewicki, R. J., \& Wiethoff, C. (2008). Making sense of intractable multiparty conflict: A study of framing in four environmental disputes. Communication Monographs, 75, 25-51. http://dx.doi.org/10.1080/03637750801952735 
Bu, T. (2009). Beijing Olympics: A new brand of China. Asian Social Science, 5(3), 84-90. http://ccsnet.org/journal.html

Campbell, M. C., \& Docherty, J. S. (2004). What's in a frame? (that which we call a rose by any other name would smell as sweet). Marquette Law Review, 87, 769-781.

Cantelon, H., \& Letters, M. (2000). The making of the IOC environmental policy as the third dimension of the Olympic movement. International Review for the Sociology of Sport, 35, 294-308. http://dx.doi.org/10.1177/101269000035003004

Chinese Olympic Committee. (2008). China and the Olympic Movement. Retrieved December 9, 2009 from Official Website of the Chinese Olympic Committee: http://en.olympic.cn/china_oly

China Daily. (2008, September 13). Olympic set to boost China's tourism: Survey. Retrieved September 23, 2011 from http://www.chinadaily.com.cn/olympics/2008-09/13/content_7024848.htm

City University of New York. (1995). Concise political history of China. Retrieved December 13, 2009 from Chinese Cultural Studies: http://academic.brooklyn.cuny.edu

Cull, N. J. (2008). The public diplomacy of the modern Olympic games and China's soft power strategy. In Price, M. E. \& Dayan, D. (Eds.) (2008). Owning the Olympics: Narratives of the new China (pp.117-144). Ann Arbor: University of Michigan Press.

Dardis, F. E. (2007). The role of issue-framing functions in affecting belief and opinions about a sociopolitical issue. Communication Quarterly, 55, 247-265. http://dx.doi.org/10.1080/01463370701290525

Davis, C., \& Lewicki, R. (2003). Environmental conflict resolution: Framing and Intractability—an introduction. Environmental Practice, 5, 200-206.

Dewulf, A., François, G., Pahl-Wostl, C., \& Taillieu, T. (2007). A framing approach to cross-disciplinary research collaboration: Experiences from a large-scale research project on adaptive water management. Ecology \& Society, 12(2), 1-24. http://www.ecologyandsociety.org/vol12/iss2/art14/

Drake, L., \& Donohue, W. (1996). Communicative framing theory in conflict resolution. Communication Research, 23, 297-322. http://dx.doi.org/10.1177/009365096023003003

Economy, E. (2007). The great leap backward? The costs of China's environmental crisis. Foreign Affairs, 86, 38-59. http://heinonline.org/HOL/LandingPage?collection=journals\&handle=hein.journals/fora86\&div=73\&id=\&page=

Edmonds, R. L. (1994). Patterns of China's lost harmony. New York: Routledge.

Entman, R. M. (1993). Framing: Towards clarification of a fractured paradigm. Journal of Communication, 43(4), 51-58. http://dx.doi.org/10.1111/j.1460-2466.1993.tb01304.x

Galotti, K. M. (2009). Cognitive Psychology: In and Out of the Laboratory (5 ${ }^{\text {th }}$ ed.). Belmont, CA: Wadsworth/Thomson Learning.

GamesBids.com. (2009). Voting Records and Results. Retrieved December 7, 2009 from Olympic Bid Election History: www.gamesbids.com/english/archives/past.shtml

Gerend, M. A., \& Shepherd, J. E. (2007). Using message framing to promote acceptance of the human papillomavirus vaccine. Health Psychology, 26(6), 745-752. http://dx.doi.org/10.1037/0278-6133.26.6.745

Gray, B. (2003). Framing of environmental disputes. In R. J. Lewicki and M. Elliot (Eds.), Making sense of intractable environmental conflicts (pp. 11-23). Washington, DC: Island Press.

Gross, K., \& D'Ambrosio, L. (2004). Framing Emotional Response. International Society of Political Psychology, 25, 1-8. http://www.jstor.org/stable/pdfplus/3792521.pdf

Hample, D., Werber, B., \& Young, D. (2009). Framing and editing interpersonal arguments. Argumentation, 23, 21-37. http://dx.doi.org/10.1007/s10503-008-9107-x

Henningsen, M. L. M., Henningsen, D. D., Cruz, M. G., \& Morrill, J. (2003). Social influence in groups: A comparative application of relational framing theory and the Elaboration Likelihood Model of persuasion. Communication Monographs, 70, 175-197. http://dx.doi.org/10. 1080/0363775032000167398

Hood, C. (2002). The risk game and the blame game. Government and Opposition, 37(1), 15-37. http://dx.doi.org/10.1111/1477-7053.00085 
Hunt, S. A., Benford, R. D., \& Snow, D. A. (1994). Identity Fields: Framing Processes and the Social Construction of Movement Idetities. In E. Larana, H. Johnston, and J. R. Gusfield (Eds.), New social movements: From ideology to identity (pp. 185-266). Philadelphia: Temple University Press.

International Olympic Committee. (2009). Factsheet on Environment and Sustainable Development. Lausanne. Retrieved Septembe 28, 2009 from the Official Website of the Olympic Movement: http://www.olympic.org/Documents/Reference_documents_Factsheets/Environment_and_substainable_dev elopement.pdf

Kanin, D. (1981). A political history of the Olympic Games, Boulder, Colorado: Westview Press.

Kraft, M. E., \& Wurtz, D. (1996). Environmental advocacy in the corridors of government. In J. G. Cantrill and C. L. Oravec (Eds.), The symbolic Earth: Discourse and our creation of the environmental (pp. 58-75). Lexington: The University Press of Kentucky.

Kurlantzick, J. (2006). China's charm: Implications of Chinese Soft Power. Carnegie Endowment for International Peace, 47, 1-27. http://carnegieendowment.org/files/PB_47_FINAL.pdf

Lakoff, G. (2004). Don't think of an elephant. White River Junction, VT: Chelsea Green Publishing.

Leiserowitz, A. (2005). American risk perceptions: Is climate change dangerous? Risk Analysis, 25, 1433-1442. http://dx.doi.org/10.1111/j.1540-6261.2005.00690.x

Liu, J., \& Diamond, J. (2005). China's Environment in a Globalizing World. Nature: International Weekly Journal of Science, 43, 1179-1186. doi:10.1038/4351179a

Manheim, J. (1990). Rites of passage: The 1988 Seoul Olympics as public diplomacy. Western Political Quarterly, 43, 270-295. http://www.jstor.org/stable/pdfplus/448367

Nielson. (2008). News release. Retrieved September 27, 2011 from http://blog.nielsen.com/nielsenwire/wp-content/uploads/2008/09/press_release3.pdf

Ong, R. (2004). New Beijing, great Olympics: Beijing and its unfolding Olympic legacy. Stanford Journal of East Asian Affairs, 4, 35-49. http://www.stanford.edu/group/sjeaa/journal42/china3.pdf

Pinker, S. (2007). The stuff of thought. New York: Viking.

Reinhart, A. M., Marshall, H. M., Feeley, T. H., Tutzauer, F. (2007). The persuasive effects of message framing in organ donation: The mediating role of psychological resistance. Communication Monographs, 74, 229-255. http://dx.doi.org/10.1080/03637750701397098

Sanders, R. (1999). The political economy of Chinese environmental protection: Lessons of the Mao and Deng years. Third World Quarterly, 20, 1201-1214. http://www.jstor.org/stable/3993666

Schlechtweg, H. P. (1996). Media frames and environmental discourse: The case of "Focus: Logjam." In J. G. Cantrill and C. Oravec, (Eds.), The symbolic Earth: Discourse and our creation of the environment (pp. 257-277). Lexington: The University Press of Kentucky.

Schlenker, B. R. (1980). Impression management: The self-concept, social identity, and interpersonal relations. Monterey, CA: Brooks/Cole.

Shanahan, J., \& McComas, K. (1999). Nature stories: Depictions of the environment and their effects. Cresskill, NJ: Hampton Press.

Shapiro, J. (2001). Mao's war against nature: Politics and the environment in revolutionary China. Cambridge and New York: Cambridge University Press.

Shmueli, D., Elliott, M., \& Kaufman, S. (2006). Frame changes and the management of intractable conflicts. Conflict Resolution Quarterly, 24, 207-218. http://dx.doi.org/10.1002/crq.169

Theodoraki, E. (2009). Organisational communication on the impacts of the Athens 2004 Olympic Games. Journal of Policy Research in Tourism, Leisure and Events, 1(2), 141-155. http://dx.doi.org/10.1080/19407960902992191

United Nations Environment Programme (2007). Beijing 2008 Olympic Games: An environmental review. Retrieved January 2, 2010 from United Nations Environment Programme: http://unep.org

United Nations Environment Programme. (1972). Environment for development. Retrieved December 8, 2009 from UNEP: www.unep.org 
Xinhua News Agency. (2008). China.org. Retrieved January 2, 2010 from Beijing Olympics showcases a mature China: http://www.china.org.cn/olympics/news

Yuan Y. (2009). Putting Down Roots. Beijing Review, 27, July 3, 2.

Zaharopoulos, T. (2007). The news framing of the 2004 Olympic Games. Mass Communication and Society, 10(2), 235-2. http://dx.doi.org/10.1080/15205430701265752

\section{(c) $\mathbf{E Y}$}

This work is licensed under a Creative Commons Attribution 3.0 License. 